\title{
MODELO MULTICRITÉRIO PARA AVALIAR A CONTRIBUIÇÃO DE INCUBADORA DE BASE TECNOLÓGICA NA GERAÇÃO DO EMPREENDEDORISMO INOVADOR
}

\author{
Ademar Dutra $^{1}$ \\ Cristina Martins ${ }^{2}$ \\ Jonas Duarte da Silva ${ }^{3}$ \\ José Carlos Martinazzo Júnior ${ }^{4}$ \\ Maicon Lacerda ${ }^{5}$
}

\section{RESUMO}

A incubadora de base tecnológica exerce um papel diferenciado no fomento ao empreendedorismo inovador, fenômeno considerado crucial na busca intensiva pelo desenvolvimento econômico e social dos países. Entretanto, não se sabe qual é a efetiva contribuição que este mecanismo gera ao empreendedorismo inovador, haja vista a inexistência de modelos que efetuem tal avaliação. Desta forma, a presente pesquisa tem por objetivo, construir um modelo multicritério de avaliação da contribuição da incubadora de base tecnológica na geração do empreendedorismo inovador. Para tal, utilizou-se como instrumento de intervenção a metodologia Multicritério de Apoio à decisão - Construtivista (MCDA-C). A pesquisa adota uma visão de conhecimento construtivista, possui caráter exploratório e se constitui em um estudo de caso. A fonte de dados é de natureza primária e secundária e a abordagem metodológica utilizada pode ser classificada como quali-quantitativa. Os resultados evidenciaram que a Metodologia Multicritério se mostrou robusta ao propiciar conhecimento quanto à construção de um modelo de avaliação que considera a incubadora um mecanismo diferenciado na promoção do empreendedorismo inovador. Além de oferecer um instrumento que possibilita gerir e transformar esforços em ações de melhorias de desempenho ao processo de empreendedorismo inovador.

Palavras-chave: Empreendedorismo Inovador. Incubadora de base tecnológica. Avaliação de desempenho. Metodologia Multicritério.

\footnotetext{
${ }^{1}$ Doutor, e-mail: ademar.unisul@gmail.com

${ }^{2}$ Graduada, e-mail: crismartins2611@gmail.com

${ }^{3}$ Especialista, e-mail: jonasduarte-s@uol.com.br

${ }^{4}$ Especialista, e-mail: josecmj@sc.senai.br

${ }^{5}$ Especialista, e-mail: maicon@sc.senai.br
} 


\section{INTRODUÇÃO}

O empreendedorismo inovador vem sendo considerado crucial na busca intensiva pelo desenvolvimento econômico e social dos países, sobretudo no que se refere a tecnologia, elemento determinante para vantagem competitiva. Percebe-se o aumento exponencial de mecanismos que estimulem este fenômeno, sendo destaque a criação de novas incubadoras de base tecnológica com crescimento equivalente a 300\% em um período de cinco anos - 2001-2006 (ASSOCIAÇÃO NACIONAL DE ENTIDADES PROMOTORAS DE EMPREENDIMENTOS INOVADORES, 2006).

Considerada mecanismo propulsor de empreendedorismo inovador, a incubadora atua promovendo um ambiente propício à criação e ao desenvolvimento de micro e pequenas empresas essencialmente inovadoras. Com isso desencadeia o desenvolvimento econômico; difunde, cria e aprimora o conhecimento; gera postos de trabalho e renda, desempenhando assim, um papel diferenciado neste processo. Contudo, avaliar essa contribuição trata-se de uma tarefa complexa, haja vista a diversidade de modelos de avaliação existentes na literatura que nem sempre auxiliam no aperfeiçoamento dos indicadores de desempenho da incubadora em relação ao seu papel na promoção das competências de inovação nas empresas incubadas.

É neste contexto que emerge a pergunta que norteará esta pesquisa: Como avaliar a contribuição de uma incubadora de base tecnológica na geração do empreendedorismo inovador?

A fim de responder à problemática, este artigo tem como objetivo construir um modelo multicritério de avaliação da contribuição da incubadora de base tecnológica na geração do empreendedorismo inovador.

A pesquisa adota uma visão de conhecimento construtivista, possui caráter exploratório, com abordagem qualitativa-quantitativa e se constitui em um estudo de caso, que objetiva identificar e aprimorar a efetiva contribuição que a incubadora de base tecnológica promove no desenvolvimento do empreendedorismo inovador, gerando assim, recomendações para melhoria de seu desempenho. No que tange à construção do modelo, a fonte de coleta dos dados é de natureza primária e secundária.

Como instrumento de intervenção, optou-se pelo uso da Metodologia MCDA-C por se tratar de uma metodologia que busca estruturar o contexto decisional, desenvolvendo modelos nos quais os decisores (ou atores) possam basear suas decisões, a partir do que eles acreditam ser o mais adequado (ENSSLIN; MONTIBELLER; NORONHA, 2001). Assim, a Metodologia MCDA-C possui aderência a realidade das incubadoras, já que são consideradas internalizadoras de relacionamento entre os atores das diferentes esferas (governo-universidade-empresas) que as envolvem, estimulando e criando espaços de interação. 
Cabe ressaltar que embora ajam outros estudos similares ao tema aqui abordado (CHALELA, 2008; GALLON; ENSSLIN; ENSSLIN, 2011; LIMA et al., 2008; MAEHLER, 2005; MANTOVANI et al., 2006; RAUPP; BEUREN, 2006), o presente trabalho difere e agrega valor por tratar de uma metodologia que além de já consolidada, considera o contexto de atuação da incubadora, suas particularidades e relacionamentos no processo de geração do empreendedorismo inovador.

Assim, este estudo pretende oferecer um processo estruturado de construção de um modelo de avaliação, fundamentado em preceitos científicos, tendo como principal foco a melhoria na performance da incubadora de base tecnológica no desenvolvimento do empreendedorismo inovador nas empresas incubadas.

Este artigo está estruturado em cinco seções, a saber: (1) Introdução; (2) Referencial Teórico; (3) Metodologia; (4) Proposta de Indicadores; e por fim, (5) Considerações finais.

\section{REFERENCIAL TEÓRICO}

Os eixos norteadores que formam o referencial teórico envolvem os temas: (i) empreendedorismo inovador; (ii) incubadora de base tecnológica; (iii) estudos similares;e, por fim (iv) modelos para avaliação de desempenho para incubadoras.

\subsection{Empreendedorismo inovador}

O termo empreendedorismo vem de Entrepreuneur, palavra americanizada, mas com derivação do francês ("entre" e "prende"), que significa "estar no mercado entre o fornecedor e o consumidor". Embora Richard Cantillon em 1755 tenha sido considerado o primeiro responsável pelo aparecimento da noção sobre o termo (DOLABELA, 1999; SARKAR, 2008; SWEDBERG, 2000) e a posteriori tenha havido a emersão de diversas outras definições e vertentes, foi somente em 1911, a partir dos estudos de Joseph A. Schumpeter que o empreendedorismo ganhou força (BARBIERI, 2003).

Economista de carreira promissora, Schumpeter é considerado o pai dos estudos sobre inovação na área de teoria econômica. Ele foi responsável pela ligação da inovação com o processo empreendedor ao definir que: um capitalista pode ser um empreendedor no momento em que realiza uma inovação, ou seja, faz uso de inovação tecnológica - como um novo produto/serviço/mercado ou processo (SCHUMPETER, 1934), mas deixa de sêlo na medida em que, estabelecida a mudança, passa a administrá-la (SCHUMPETER, 1982). 
Esta clássica definição do autor que só considera empreendedor, aquele que inova, já sinalizava a necessidade de um olhar mais amplo sobre o empreendedorismo, de forma a contemplar outros elementos e perspectivas que não somente o processo de criação de empresas. Emergia então, a relação com um poderoso instrumento que está intimamente integrado ao empreendedorismo, trabalhando em simbiose, a inovação (FARBER; HOELTGEBAUM; KLEMZ, 2011).

A partir do estabelecimento da inovação como fator chave (RAUPP; BEUREN, 2009) para o reconhecimento do espírito empreendedor (DRUCKER, 2010), autores mais contemporâneos como Sarkar (2008) afirmam que a definição de inovação, é o mesmo que atualmente se entende por empreendedorismo. Desta forma, importa esclarecer que o empreendedorismo passa a ser tanto percebido, como medido por meio da inovação, e por isso, embora considerado um termo redundante, vem sendo chamado como "empreendedorismo inovador".

Neste contexto, muitas das inovações acontecem a partir de iniciativas individuais ou de pequenos grupos com interesses, habilidades e motivação para realizar o novo. O que possibilita reconhecer que muitos dos resultados nestes termos decorrem da existência de um ambiente geral favorável à inovação, ou seja, por meios que a condicionem (TERRA, 2010).

Dentre estes aspectos promotores da inovação, destaca-se a importância de criar mecanismos de desenvolvimento e de geração de novas empresas, visto que estes podem resolver muitos problemas sociais, tais como emprego e renda.

É neste sentido que a Associação Nacional de Entidades Promotoras de empreendimentos Inovadores (2004, p.7) ressalta:

projetos e iniciativas adotadas por muitos municípios no Brasil que estão obtendo sucesso no desenvolvendo de suas regiões por meio de soluções que estão se consolidando como verdadeiras "alavancas" do empreendedorismo inovador, tal como: a incubadora de base tecnológica.

Mas, o que é a incubadora de base tecnológica?

\subsection{Incubadora de base tecnológica}

Considerada "Símbolo físico do empreendedorismo e da inovação" (ASSOCIAÇÃO NACIONAL DE ENTIDADES PROMOTORAS DE EMPREENDIMENTOS INOVADORES, 2004) a incubadora de empresa é um ambiente dotado de capacidade técnica, gerencial, administrativa e infraestrutura para amparar o pequeno empreendedor (ASSOCIAÇÃO NACIONAL DE ENTIDADES PROMOTORAS DE EMPREENDIMENTOS INOVADORES, 2006). Ela disponibiliza espaço apropriado e condições efetivas para abrigar ideias inovadoras e transformá-las em empreendimentos de sucesso. 
A incubadora de base tecnológica (IBT) visa à promoção do desenvolvimento de empresas de base tecnológica, em outras palavras, é um local propício para viabilização de empresas inovadoras, cujos produtos desenvolvidos detém alto conteúdo científico, gerando externalidades altamente positivas para o seu entorno (BAÊTA, 1999).

Nesse âmbito, chamada debridge-institution (PINTO, 2006) e considerada como organização híbrida no modelo de hélice tríplice de relações universidade-empresagoverno, a IBT internaliza o relacionamento entre as esferas, estimulando e criando um espaço de interação. Capaz de aumentar a taxa de inovação e de criatividade, tanto em nível organizacional, quanto no tecnológico, a incubadora assume o papel previsto de se colocar como dinamizadora do desenvolvimento econômico com base no conhecimento produzido no seu interior (ARANHA, 2008; ETZKOWITZ, 2002).

Corroborando com tal afirmação, uma pesquisa realizada pela ASSOCIAÇÃO NACIONAL DE ENTIDADES PROMOTORAS DE EMPREENDIMENTOS INOVADORES (2002), revela que dos objetivos para a existência das incubadoras, que de certo modo mostram os benefícios perseguidos pela sua criação, o incentivo ao empreendedorismo (88\%) está na primeira posição, seguido do desenvolvimento econômico (72\%), desenvolvimento tecnológico (70\%), geração de empregos (61\%), a diversificação da economia regional (48\%) e, por último, o lucro (32\%).

Jabour, Dias e Fonseca (2004) acrescentam ainda que a incubadora é um local propício para geração de redes empresariais em favor da inovação e da partilha de conhecimentos específicos e gerais das quais diversos agentes participam. Ela fortalece as chances de sobrevivência e crescimento das empresas, constituindo-se em uma oportunidade única de aprendizagem compartilhada, sendo a cultura aberta a cooperação uma importante fonte de vantagens competitivas (KANTER; KAO; WIERSEMA, 1998; LUNDVALL, 1992).

Cabe ressaltar que esta participação dinâmica que a incubadora propicia por meio de arranjos ou sistemas produtivos locais ou nacionais tem auxiliado as empresas, especialmente as de micro, pequeno e médio portes a ultrapassarem as conhecidas barreiras ao crescimento, a produzirem eficientemente e a comercializarem seus produtos em mercados nacionais e até internacionais (LASTRES; CASSIOLATO, 2003).

\subsection{Estudos similares}

Mediante a importância da incubadora de base tecnológica demonstrada no decorrer deste artigo, buscou-se elencar estudos a respeito da mesma temática a fim conhecer as características e confrontar possíveis similaridades ou divergências com o que se objetiva. Com tal finalidade o quadro 1 expõe uma síntese de estudos similares e suas características. 


\begin{tabular}{|c|c|c|}
\hline AUTORES & OBJETIVOS DA PESQUISA & CARACTERISTICAS DA PESQUISA \\
\hline $\begin{array}{l}\text { MAEHLER, A.E. } \\
(2005) \text {. }\end{array}$ & $\begin{array}{l}\text { Identificar comose dá a interação e } \\
\text { quais as contribuiçőes da } \\
\text { Incubadora Tecnológica de Santa } \\
\text { Maria (ITSM) e da Universidade } \\
\text { Federal de Santa Maria (UFSM) } \\
\text { para o desenvolvimento e } \\
\text { fortalecimento das empresas de } \\
\text { base tecnológica incubadas e } \\
\text { graduadas na ITSM. }\end{array}$ & $\begin{array}{l}\text { Traça o perfil da ITSM, UFSM, empresas } \\
\text { incubadas e graduadas e seus respectivos } \\
\text { gerentes. } \\
\text { Estuda a interação /contribuição da } \\
\text { Incubadora (ITSM) e da universidade } \\
\text { (UFSM) na visão do gerente ITSM, } \\
\text { professores (UFSM) e empresánios } \\
\text { (incubados e graduados). } \\
\text { Elenca as Barreiras de desenvolvimento } \\
\text { dasempresas incubadas ou graduadas na } \\
\text { visão do gerente ITSM, professores } \\
\text { (UFSM) e empresános (incubados e } \\
\text { graduados). }\end{array}$ \\
\hline $\begin{array}{l}\text { MANTOVANI, } \\
\text { D.M. } \\
\text { GRANITO, } \\
\text { R.A.N.; } \\
\text { CABRAL, D.G; } \\
\text { LEITE, M.F.B. } \\
\text { (2006). }\end{array}$ & $\begin{array}{l}\text { Estudar as atividades desenvolvidas } \\
\text { por uma incubadora de empresas, } \\
\text { localizada na região de Ribeirão } \\
\text { Preto, avaliando seus impactos } \\
\text { sobre as empresas incubadas, } \\
\text { graduadas e comunidade local em } \\
\text { geral. }\end{array}$ & $\begin{array}{l}\text { Aborda o papel que as incubadoras } \\
\text { exercem no desenvolvimento de micro e } \\
\text { pequenas empresas. } \\
\text { Enfatiza a importância das micro e } \\
\text { pequenas para a economia nacional. } \\
\text { Foco no desenvolvimento local. }\end{array}$ \\
\hline $\begin{array}{l}\text { RAUPP, F.M.; } \\
\text { BEUREN, I.M. } \\
(2006) \text {. }\end{array}$ & $\begin{array}{l}\text { Verificar o suporte que as } \\
\text { incubadoras brasileiras oferecemàs } \\
\text { empresas incubadas no sentido de } \\
\text { potencializar suas caracteristicas } \\
\text { empreendedoras na perspectiva de } \\
\text { seus coordenadores. }\end{array}$ & $\begin{array}{l}\text { - Analisa o perfil das incubadoras } \\
\text { brasileiras. } \\
\text { Requisitos para instalação de } \\
\text { empreendimentosnas incubadoras. } \\
\text { Suporte das incubadoras às empresas } \\
\text { incubadas. }\end{array}$ \\
\hline $\begin{array}{l}\text { CHALELA, L.R. } \\
\text { (2008). }\end{array}$ & $\begin{array}{l}\text { Verificar a atuação empreendedora } \\
\text { e inovadora nos ambientes de } \\
\text { incubação. }\end{array}$ & $\begin{array}{l}\text { Explora incubadoras de empresa de base } \\
\text { tecnológica. } \\
\text { Analisa o perfil de dinigentes das empresas } \\
\text { incubadas (selecionadas). } \\
\text { - Caracteriza o Ecossistema das empresas } \\
\text { incubadas. }\end{array}$ \\
\hline $\begin{array}{l}\text { LIMA, A.A. T; } \\
\text { ALBINO, A.A.; } \\
\text { OLIVEIRA, J. L. } \\
\text { C.; OLIVEIRA, } \\
\text { R.S. (2008). }\end{array}$ & $\begin{array}{l}\text { Investigar os modelos de avaliação } \\
\text { para avaliação de incubadoras de } \\
\text { empresas de base tecnológica a luz } \\
\text { da inovação tecnológica. }\end{array}$ & $\begin{array}{l}\text { - Analisa os modelos do PNI; } \\
\text { CAMBRIDGE e MORAIS. } \\
\text { Efetua reflexões sobre os modelos citados } \\
\text { no item acima, elencando os principais } \\
\text { pontos fortes e fracos de cada modelo. }\end{array}$ \\
\hline $\begin{array}{lr}\text { GALLON, } & \text { A.V; } \\
\text { ENSSLIN, } & \text { R.S.; } \\
\text { ENSSLIN, } & \text { L. } \\
(2011) . & \end{array}$ & $\begin{array}{l}\text { Construir um modelo multicritério } \\
\text { de avaliação do desempenho do } \\
\text { MIDI Tecnológico, por meio da } \\
\text { Metodologia MCDA-C. }\end{array}$ & $\begin{array}{l}\text { Foco na avaliação e gerenciamento de } \\
\text { investimentos realiza dos pelaincubadora. } \\
\text { - Analisado perfil de desempenho do } 2^{\circ} \\
\text { semestre } / 2007 \text { e do } 1^{\circ} \text { semestre } / 2008 \text {. }\end{array}$ \\
\hline
\end{tabular}

Conforme o quadro1, foi localizado alguns estudos já realizados sobre as incubadoras. Contudo, apesar de aspectos comuns, suas abordagens atinham-se a avaliar a contribuição da incubadora de base tecnológica a partir: da caracterização de perfis específicos; da interação com a universidade e micro e pequenas empresas; do suporte às empresas incubadas; da visão de dirigentes; e, da avaliação de investimentos. O que proporciona 
inferir que há um consenso entre os autores sobre a contribuição da incubadora de base tecnológica às micro e pequenas empresas (empresas incubadas/graduadas). Entretanto, não se percebe ênfase por estes autores na construção de um modelo multicritério que avalie o processo de desenvolvimento do empreendedorismo inovador gerado pela incubadora de base tecnológica, levando em consideração a interação com diversos atores em um aspecto mais amplo, não apenas de uma perspectiva de investimentos ou suporte, mas sim de um senso global que mensure esse desempenho no processo como um todo e que em paralelo não deixe de explorar as particularidades dos objetos de estudo.

Em face ao exposto, parece pertinente compreender os modelos de avaliação de incubadoras apresentados pela literatura, a fim de auxiliar no cumprimento do objetivo deste artigo, o que motiva a abordagem do tópico a seguir.

\subsection{Modelos para avaliação de desempenho de incubadoras}

Embora se tenha uma diversidade de métodos, dimensões e indicadores que proponham a avaliação de desempenho no contexto das incubadoras, estes modelos não enfatizam a contribuição da incubadora de base tecnológica no processo de desenvolvimento do empreendedorismo inovador, conforme se pode verificar no quadro 2.

Quadro 2: Síntese das propostas para a avaliação do desempenho de incubadoras

\begin{tabular}{|c|c|c|}
\hline Modelos & Consideraçōes Gerais & Exemplo de variáveis \\
\hline $\begin{array}{l}\text { Proposta do MCT } \\
\text { (1998) }\end{array}$ & $\begin{array}{l}\text { O MCT (1998) sugere ainda que seja efetuada a avaliação } \\
\text { de impacto social e econômico da incubadora em duas } \\
\text { fases, quais sejam, quando as empresas adquirem condição } \\
\text { de graduadas, saindo da incubadora, em média, após dois } \\
\text { anos de incubação; e quando as empresas graduadas } \\
\text { atingem a maturidade, consolidada após três anos de } \\
\text { graduação. }\end{array}$ & $\begin{array}{l}\text { - A eficiência na gestão dos recursos } \\
\text { recebidos; } \\
\text { - A eficácia e o impacto do empreendimento } \\
\text { quanto à execução dos objetivos e metas } \\
\text { realizados, considerando o planejamento } \\
\text { apresentado. }\end{array}$ \\
\hline $\begin{array}{l}\text { Proposta do PNI } \\
\text { (DORNELAS, } \\
\text { 2002) }\end{array}$ & $\begin{array}{l}\text { O PNI sugere um conjunto de indicadores de desempenho } \\
\text { que, segundo Dornelas (2002), deve ser variável } \\
\text { componente em qualquer programa de avaliação de } \\
\text { incubadoras, visto que é considerado como referência sobre } \\
\text { o assunto no Brasil. O diferencial desse conjunto de } \\
\text { indicadores é o fato de considerar três fases do ciclo de } \\
\text { incubaçãa, quais sejam, pré-incubação, incubação e pós- } \\
\text { incubação, sendo que para cada uma destas fases criou-se } \\
\text { um grupo pertinente de indicadores (DORNELAS, 2002). }\end{array}$ & $\begin{array}{l}\text { - Pré-incubação: número de pedidos de } \\
\text { registros no INPI-Instituto Nacional da } \\
\text { Propriedade Industrial, oriundos de projetos } \\
\text { em pré-incubação; } \\
\text { - Incubação: tempo médio de incubação; taxa } \\
\text { de crescimento anual do faturamento das } \\
\text { empresas incubadas; } \\
\text { - Pós-incubação: taxa de crescimento do } \\
\text { faturamento. }\end{array}$ \\
\hline $\begin{array}{c}\text { Proposta de } \\
\text { Markley e } \\
\text { McNamara } \\
\text { (apud } \\
\text { DORNELAS, 2002) } \\
\end{array}$ & $\begin{array}{l}\text { Mensurar impactos econômicos e fiscais gerados por } \\
\text { empresas incubadas e graduadas }\end{array}$ & $\begin{array}{l}\text { Retorno do investimento público em } \\
\text { incubadoras a partir do enfoque da geração de } \\
\text { renda e empregos; investimento público em } \\
\text { incubadoras, versus arrecadação fiscal das } \\
\text { mesmas. }\end{array}$ \\
\hline $\begin{array}{l}\text { Proposta de } \\
\text { Morais } \\
(1997)\end{array}$ & $\begin{array}{l}\text { O modelo visa: a) avaliar o impacto socioeconômico e } \\
\text { cultural das incubadoras e empresas incubadas no } \\
\text { desenvolvimento regional ou local; b) induzir a aplicação de } \\
\text { técnicas gerenciais no processo de gestão dos pequenos } \\
\text { empreendimentos de forma a fomentar probabilidades de } \\
\text { êxito; c) construir indicadores de avaliação da performance } \\
\text { das incubadoras que sejam úteis para as instituições } \\
\text { apoiadoras desses programas. }\end{array}$ & $\begin{array}{l}\text { - Empresas graduadas por ano; inovações } \\
\text { registradas por empresa incubada; relação } \\
\text { candidato por vaga na incubadora }\end{array}$ \\
\hline
\end{tabular}


Observa-se no quadro acima, a falta de critérios estruturados, o que dificulta avaliar os impactos tecnológicos dos programas de incubação da eficiência das incubadoras como mecanismo de inovação tecnológica, bem como, das contribuições para a consolidação do sistema de inovação (VEDOVELLO; FIGUEREDO, 2005). Adicionalmente, Motta e Imoniana (2005, p. 68) afirmam que no contexto das incubadoras "ainda existem lacunas metodológicas para avaliação do desempenho e para possibilitar a melhora de sua eficácia".

\section{MÉTODOS DA PESQUISA}

Com o intuito de atingir o objetivo da pesquisa, optou-se por dividir a metodologia em: (i) enquadramento metodológico e (ii) instrumento de intervenção.

\subsection{Enquadramento metodológico}

Do ponto de vista metodológico esta pesquisa enquadra-se: (i) quanto à filosofia da pesquisa, como construtivista; (ii) quanto à abordagem metodológica, como qualitativa/ quantitativa; (iii) quanto ao objetivo, como exploratória; e, (iv) quanto à estratégia, como estudo de caso. No que se refere a coleta de dados, envolve tanto dados primários, como secundários.

A filosofia da pesquisa construtivista, na visão de Roy (1993), consiste em considerar conceitos, modelos, procedimentos e resultados como "chaves" capazes, ou não, de abrir certos bloqueios, que os torna apropriados para organizar e desenvolver conhecimento de uma situação. O construtivismo pressupõe a noção de produção de conhecimento com base na participação dos atores no processo. Nesse sentido, não há uma verdade a ser descoberta, mas o conhecimento é construído a partir do sistema de valor, conviç̧ões e objetivos daqueles que estão envolvidos no processo. Assim, a construção do modelo de avaliação para identificar a contribuição de incubadora de base tecnológica na geração do empreendedorismo inovador levará em consideração as percepções do decisor envolvido no contexto.

Quanto à abordagem metodológica, o enquadramento desta pesquisa como qualitativa/ quantitativa segue os preceitos recomendados por Merriam (1998), o qual esclarece que a pesquisa qualitativa preza pelo interesse em entender o significado das sensações e sentimentos vivenciados pela experiência humana, presente na pesquisa na etapa de estruturação do modelo de avaliação do empreendedorismo inovador, enquanto a pesquisa quantitativa vale-se de ferramentas estatísticas e matemáticas como instrumento de trabalho, presente na utilização de escalas ordinais e cardinais para mensurar, avaliar e agregar o desempenho da incubadora, nos termos da Metodologia MCDA-C. 
No que se refere aos objetivos, este trabalho enquadra-se como exploratório, devido a sua característica de buscar uma maior aproximação com o objeto de estudo, permitindo a geração de conhecimentos que possibilite a construção do modelo de avaliação. De acordo com (GIL, 1991, p.45) este tipo de pesquisa "têm como objetivo proporcionar maior familiaridade com o problema, com vistas a torná-lo mais explícito ou a construir hipóteses".

Em relação ao enquadramento da estratégia, definiu-se esta pesquisa como estudo de caso, já que o foco do pesquisador é caracterizar o desempenho de uma incubadora de base tecnológica, levando em consideração o contexto em que está inserida. Desta forma, Gil (1991) esclarece que o estudo de caso consiste na seleção de um único ou poucos objetos de pesquisa passíveis de aprofundamento.

Quanto a coleta de dados utilizou-se dados primários, por meio de entrevistas semiestruturadas com o decisor e dados secundários, através da análise documental inerente a regulação e funcionamento de uma incubadora de base tecnológica (RICHARDSON,1999).

\subsection{Instrumento de intervenção}

A metodologia Multicritério de Apoio à Decisão Construtivista - MCDA-Cé um instrumento de apoio à decisão que tem sua validade científica comprovada por vários trabalhos publicados em periódicos de destaque no cenário nacional e no internacional, tais como: EuropeanJournalofOperationalResearch; Management Decision; InternationalJournalof Productivity andPerformance Management; Pesquisa Operacional; Gestão \& Produção; Revista Brasileira de Gestão de Negócios; Produção Online; Produção, Revista Contemporânea de Contabilidade, entre outras (BORTOLUZZI, ENSSLIN e ENSSLIN. 2011; DUTRA et al., 2009; ENSSLIN et al., 2010; LACERDA, ENSSLIN e ENSSLIN, 2011a; LACERDA, ENSSLIN e ENSSLIN, 2011b; MORAES et al., 2010; VEGINI et al., 2012).

De acordo com Zamcopé et al., (2010) a Metodologia MCDA-C surge como uma evolução da Metodologia Multicritério em Apoio à Decisão - MCDA, objetivando apoiar os decisores em contextos complexos, conflituosos, incertos, em que esses desejavam melhorar seu entendimento da situação.

Roy (1996) ainda complementa que os pesquisadores em MCDA, dividem-se em dois grupos: aqueles que utilizam a lógica da pesquisa racionalista dedutiva (MCDA tradicional); e, aqueles que utilizam a lógica construtivista mista (indutiva e dedutiva) (MCDA-C). Ressalta-se que alguns adeptos da visão construtivista têm dificuldades de operacionalizar a etapa de estruturação de forma a reconhecer os limites da objetividade e então, autores que contemplam esta etapa, designaram MCDA-C a forma de enfatizar a diferença da lógica de pesquisa (ENSSLIN et al., 2010). 
Neste contexto, optou-se pela MCDA-C, pois além de filiar-se as convicções e conceitos, ela proporcionará uma melhor capacidade de compreensão das percepções dos múltiplos atores envolvidos no processo de desenvolvimento do empreendedorismo inovador a partir da incubadora de base tecnológica. Este cenário caracteriza-se como uma situação complexa, pois cada um desses atores tem seu sistema de valores, diversos objetivos com conflitos de interesses, diferentes níveis de poder, além de uma enorme gama de informações qualitativas e quantitativas (CHURCHILL, 1990, apud ENSSLIN; MONTIBELLER; NORONHA, 2001).

Para tal, a estruturação do MCDA-C é dividida em três fases, conforme demonstra figura 1.

Figura 1: Fases do processo MCDA-C

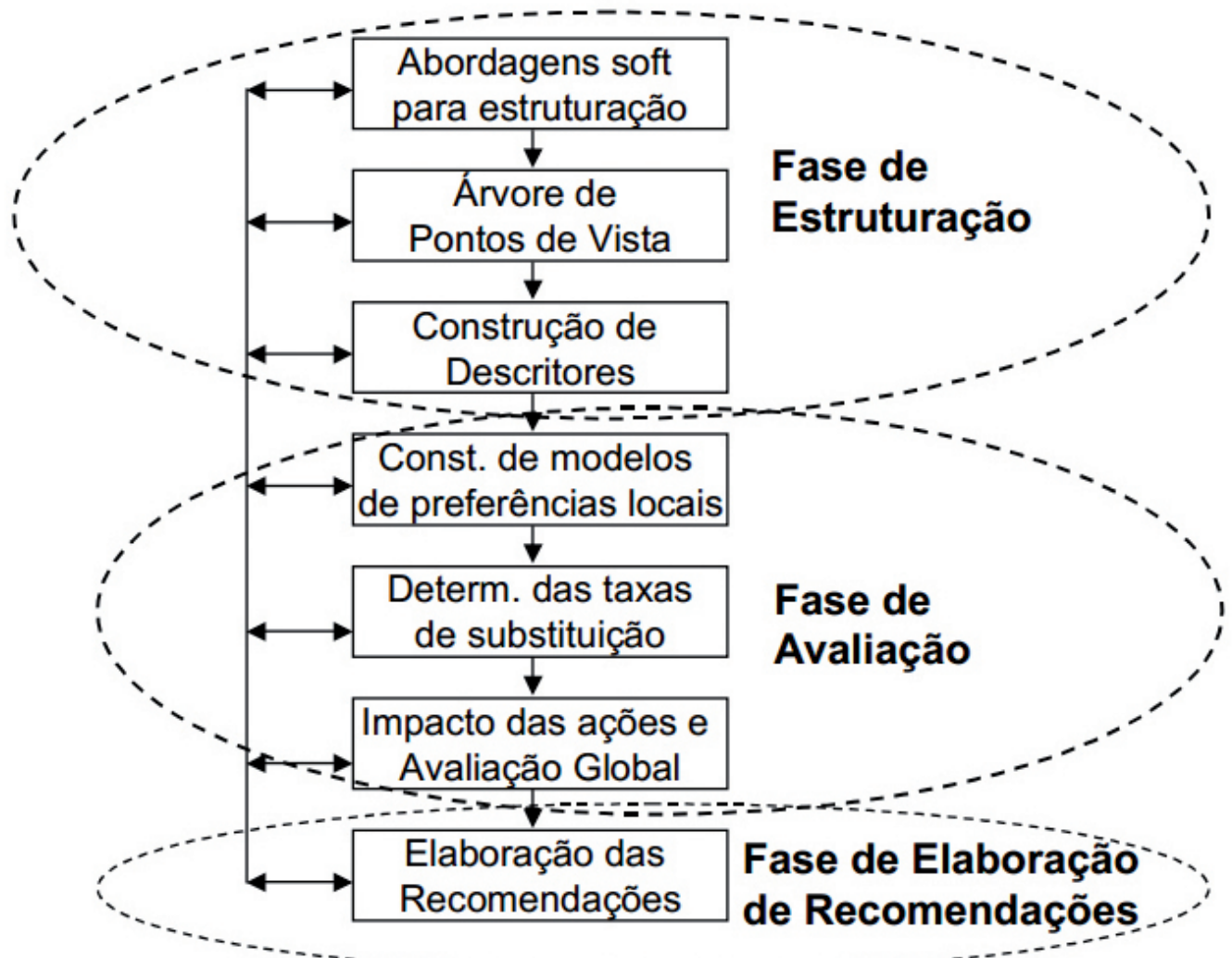

Fonte: Ensslin, Dutra e Ensslin (2000, p. 81) 
E, cada fase se desdobra em etapas, a saber:

1) Estruturação: procura identificar e organizar os fatores relevantes a respeito do contexto decisional e se subdivide em: (i) caracterização do contexto (apresentar o ambiente onde o problema está inserido, identificando também os atores e suas percepções atuais e pretendidas); (ii) árvore de ponto de vistas ou construção da estrutura hierárquica (consiste em identificar os critérios a serem avaliados); (iii) construção dos descritores (a construção das escalas ordinais de mensuração);

2) Avaliação: objetiva a tradução da percepção do decisor em um modelo matemático e se divide em: (i) construção do modelo de preferência local e (ii) determinação das taxas de substituição (construção de uma função de valor que represente as preferências do decisor em relação a um determinado critério); (iii) avaliação global (agregação das avaliações locais em um critério único de síntese).

3) Elaboração das recomendações: consiste na sugestão de ações potenciais que visam melhorar o desempenho em relação à situação atual.

Durante todo processo de construção do modelo, considerando as características de cada área, as diretrizes estabelecidas, e tomando por base a proposta de Ensslin et al., (2007), a equipe de trabalho buscou definir: (i) o que medir - envolver os participantes para estabelecer o que é importante em cada área e os objetivos a serem perseguidos; (ii) como medir - a tradução do "o que medir" em termos objetivos, por meio da construção de escalas;(iii) os padrões de referência e mensuração - níveis de referência que possibilitaram a compreensão da performance do desempenho em nível de Excelência, Competitividade e Comprometimento, em cada indicador do modelo concebido; (iv) como efetuar a avaliação - a operacionalização da avaliação, ou seja, a coleta, classificação e análise das informações; e, por fim, (v) a avaliação de desempenho propriamente dita.

\section{ANÁLISE DOS RESULTADOS}

Esta seção apresenta a construção do modelo de avaliação do desempenho da contribuição da incubadora de base tecnológica no desenvolvimento do empreendedorismo inovador, pautando-se na Metodologia MCDA/C. 


\subsection{Identificação do contexto decisório}

Inicia-se a construção do modelo caracterizando o processo decisório em que o Apoio à Decisão irá ocorrer, bem como os atores envolvidos, as ações a serem avaliadas e as diversas alternativas de avaliação das ações (HMELJEVSKI, 2007).

Cabe ressaltar que a construção do modelo se trata de uma proposição, e que sua implementação pode requerer alguns ajustes, já que não se delimitou para qual incubadora o modelo está sendo construído. É destacado também, o recorte da avaliação que enfoca somente a demonstração do desempenho de algumas das áreas, e seu impacto sobre o desempenho num todo.

Assim, um dos autores do presente estudo, com formação e experiência na área de tecnologia da informação atuou como decisor, enquanto os demais exerceram o papel de facilitadores. Desta forma, os autores da presente pesquisa atuaram como decisor e facilitadores, tendo como interveniente as universidades e o governo nas três esferas constituídas e agidos as empresas incubadas e/ou graduadas, além da comunidade local e regional.

\subsection{Estruturação do problema}

Identificado o contexto, partiu-se para a problemática fundamentada pelo decisor no reconhecimento de quatro premissas: (i) que a incubadora de base tecnológica provê um ambiente propício a criação e desenvolvimento de micro e pequenas empresas essencialmente inovadoras, pois fornece um leque de serviços diferenciados, espaço físico, bem como potencializa a interação entre redes de relacionamento; (ii) que o processo de incubação promovido pela incubadora é crucial para que a inovação se concretize em tempo hábil a cumprir as demandas do mercado e assim desencadear o desenvolvimento econômico; (iii) que a incubadora é ator importante para a difusão de conhecimento e a melhoria da qualidade de vida por meio da geração de postos de trabalho e renda; e, (iv) que o desempenho da incubadora de base tecnológica alavanca o processo de empreendedorismo inovador. Entretanto, mesmo conscientes das contribuições geradas pela incubadora, não se sabe efetivamente o seu desempenho no fomento do empreendedorismo inovador, o que subsidiouao decisor (definido anteriormente como um dos autores)levantar a seguinte problemática: como avaliar a contribuição da incubadora de base tecnológica na geração do empreendedorismo inovador?

A partir da definição do problema, é necessário realizar a formulação de um rótulo, ou seja, um nome que melhor represente as percepções do decisor e que descreva o problema em que o facilitador irá apoiar na resolução. Neste caso, definiu-se o seguinte rótulo: "construir um modelo para avaliar o desempenho de incubadora de base tecnológica no processo de desenvolvimento do empreendedorismo inovador". 


\subsection{Estruturação do modelo MCDA/C}

Nestas etapas e identificaram junto ao decisor por meio brainstorming (OSBORN, 1993) os Elementos Primários de Avaliação (EPA).Os EPAS são as primeiras preocupações apontadas que influenciam no desempenho da incubadora em relação ao empreendedorismo inovador e que constituídas de objetivos, metas, alternativas, fundamentarão a construção do mapa cognitivo (ZANELATO, 2008).

Desta forma, o quadro 3 exemplifica três dos 53 EPAs elencados pelo decisor. Para cada EPA construiu-se os seus respectivos conceitos, isso é, identificou-se os polos presentes (o que se pretende) e os pólos opostos (mínimo aceitável pelo decisor).

Quadro 3: Exemplos de EPAs e conceitos

\begin{tabular}{|l|l|}
\hline EPAS & Conceito \\
16. Avaliarconsultorias & $\begin{array}{l}\text { Avaliar se as atividades de consultorias } \\
\text { estão contribuindo para fomentar o } \\
\text { empreendedorismo inovador... Nãoavaliar } \\
\text { Oferecer serviços de consultoria jurídica } \\
\text { 50. Consultoriajurídica e de } \\
\text { propriedade intelectual }\end{array}$ \\
$\begin{array}{l}\text { 51. Portfólio de serviços de inovação prodade intelectual... Manter as } \\
\text { atuais }\end{array}$ \\
$\begin{array}{l}\text { Ampliar o portfólio de serviços de inovação... } \\
\text { Manter as atuais }\end{array}$ \\
\hline
\end{tabular}

Fonte: Dos autores (2012)

A posteriori, organizaram-se os EPAs e seus respectivos conceitos por áreas de concentração, formando assim, um modelo global, composto por seis grandes áreas. Algumas destas seis grandes áreas foram desmembradas em subáreas de concentração, a saber: (i) área de concentração Desenvolvimento de Competências que resultou em quatro subáreas; e, (ii) área de concentração Resultados que foi desmembrada em três subáreas, conforme ilustra a estrutura hierárquica da Figura 2. 
Figura 2: Agrupamento dos conceitos em áreas de preocupação

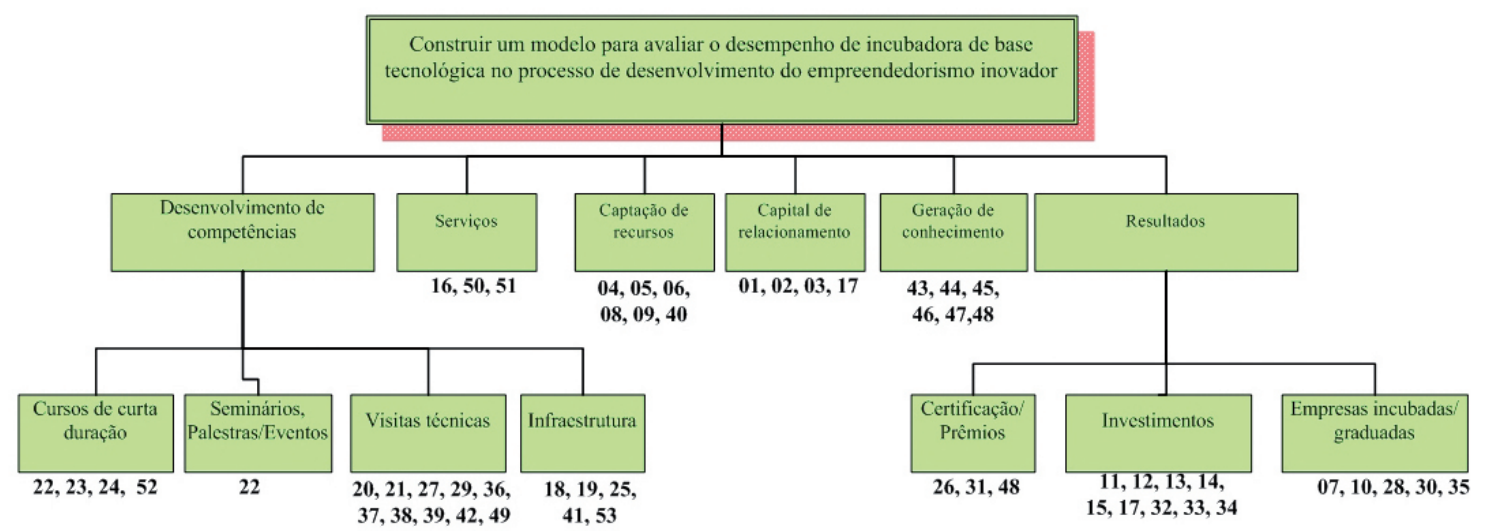

Fonte: Dos autores (2012)

A partir dos agrupamentos realizados, partiu-se para a construção dos mapas cognitivos de cada área de concentração. De acordo com Montibeller (2000), um mapa cognitivo se trata de uma hierarquia de conceitos, relacionados por ligações de influencia entre meios e fins. A construção deste mapa auxiliará o decisora expandir os conhecimentos sobre o contexto, por meio da explicitação de seus valores relacionados ao problema em questão, além de fornecer os meios para atingir os fins almejados, conforme ilustra a figura 3, da área de concentração "Serviços" (vide Figura 3).

Figura 3: Mapa cognitivo da área "Serviços"

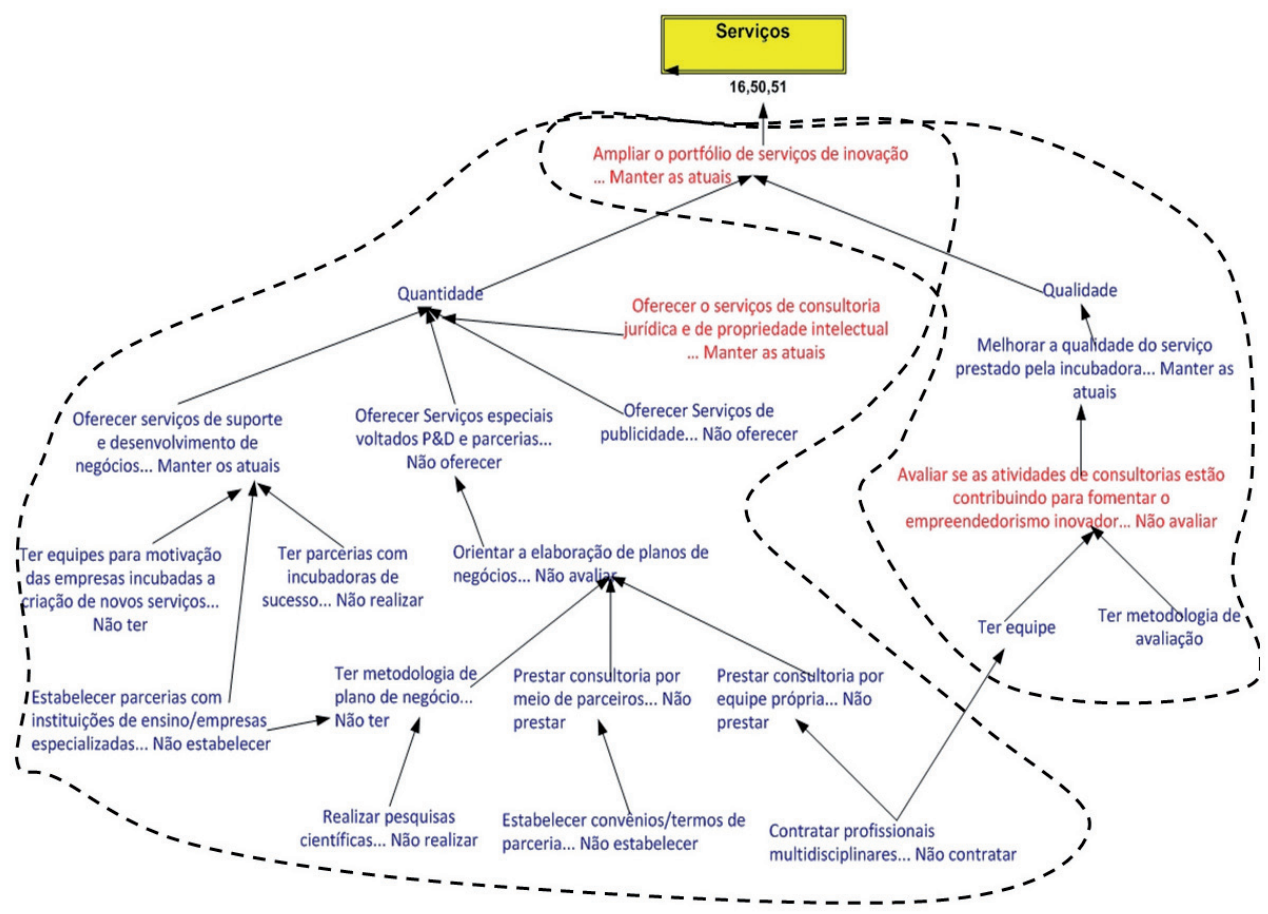

Fonte: Dos autores (2012) 
Concluída a construção do mapa cognitivo, seguiu-se para identificação dos clusters ilustrados pela linha pontilhada da figura 3. A deteç̧ão de clusters foi realizada manualmente pelos facilitadores e validada pelo decisor, por meio do agrupamento dos conceitos que em sua percepção têm sentido semelhante, ou seja, são da mesma natureza e que representam a área de interesse. Cabe enfatizar que o cluster permite uma visão macro do mapa cognitivo, sendo, portanto de grande relevância para sua análise (ENSSLIN; MONTIBELLER; NORONHA, 2001). Em cada cluster foram identificados os ramos de acordo com as linhas de argumentação, que representam um conjunto de conceitos que demonstram as preocupações similares no contexto decisório (DUTRA, 1998).

Conforme supracitado, os mapas cognitivos seguem uma estrutura de meios e fins e esta se difereda estrutura arborescente apresentada por outros modelos multicritério (BELTON, 1990), fazendo então, com que haja uma transição que se dá pela identificação das dimensões sinalizadas pelo decisor como importantes e suficientes para representação do problema. E a esse conjunto de dimensões denomina-se Família de Ponto de Vistas Fundamentais (PVFs) (ENSSLIN; MONTIBELLER; NORONHA, 2001).

Os PVFs são aspectos considerados pelo decisor como imprecindíveispara avaliar as ações potencias - as incubadoras de base tecnológica -explicitando valorese percepções que o decisor considera relevante em seu contexto, em outras palavras que se caracterizam como os eixos de avaliação do problema (GIFFHORN, 2007).

Com a operacionalização dos mapas cognitivos para cada PVF, obteve-se a estrutura arborecente completa do contexto decisional, objeto desta pesquisa, o qual é exemplificadopela Figura 4.

Figura 4: PVFs Serviços e seus respectivos PVEs

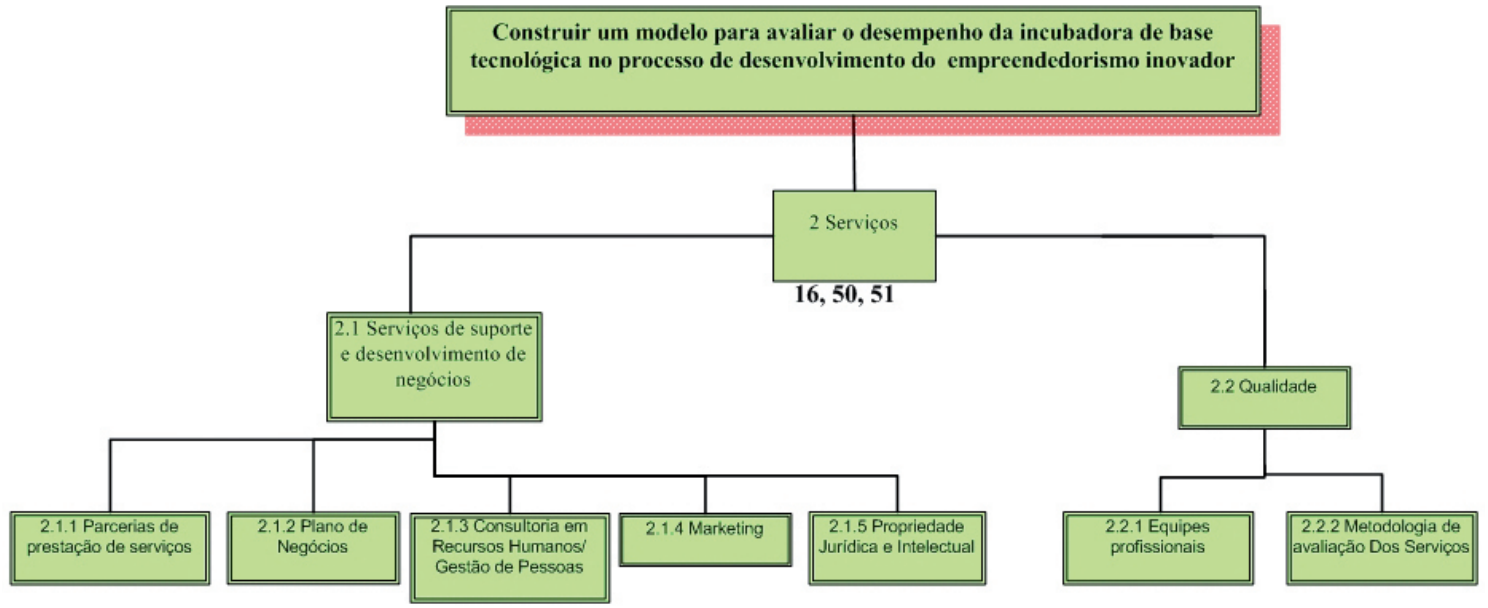

Fonte: Dos autores (2012) 
Constata-se acima que o PVF 2. Serviços foi desdobrado em dois PVE'S. O PVE 2.1 Serviços de Suporte e Desenvolvimento de Negócios é representado por cinco Pontos de Vistas Elementares denominados: 2.1.1 Parcerias de prestaçãso de serviços; 2.1.2 Plano de Negócios; 2.1.3 Consultoria em Recursos Humanos / Gestão de Pessoas; 2.1.4 Marketing; e, 2.1.5 Propriedade Jurídica e Intelectual. O PVE 2.2 Qualidade foi desmembrado nos PVE's 2.2.1 Equipes Profissionais e 2.2.2 Metodologia de Avaliação de Serviços.

Com a identificação dos PVFs, devidamente representados na estrutura arborescente por meio da lógica de decomposição, em que um critério mais complexo de se mensurar é desmembrando em subcritérios de mais fácil mensuração, denominado Ponto de Vista Elementar (PVE), partiu-separa a construção dos descritores e suas funções de valor. Os descritores são representados pelo último nível hierárquico da estrutura arborescente, ou seja, estão posicionados em direção aos "meios" considerando o processo de estruturação do contexto decisório.

Também chamados de atributos (KEENEY, 1992) e referenciados na lituratura científica como indicadores, os descritores são um conjunto de níveis de impacto que servem como base para descrever as performances plausíveis das ações potenciais em termos de cada PVF (BANA e COSTA, 1992). As ações potenciais são representadas pelas diversas incubadoras de base tecnológica, objeto de contrução do modelo.

A seguir, na Tabela 1, apresenta-se a construção do descritor 2.2.2 Metodologia de Avaliação dos Serviços.

Tabela 1: Descritor 2.2.2 Metodologia de avaliação dos serviços e seus níveis de impacto

\begin{tabular}{l|l|l}
\hline 2.2.2 Metodologia de avaliação dos Serviços \\
\hline Níveis de Impacto & Níveis de Referência & Descrição \\
\hline N5 & BOM & $\begin{array}{l}\text { De forma contínua, por meio de formulário } \\
\text { padronizado } \\
\text { De forma mensal por meio de formulário } \\
\text { padronizado } \\
\text { De forma anual por meio de formulário } \\
\text { padronizado } \\
\text { Inexiste processo estruturado } \\
\text { Nossui informações dispersas }\end{array}$ \\
\hline N1 & NEUTRO &
\end{tabular}

Fonte: Dos autores (2012) 
O descritor (Tabela 1) foi estruturado em cinco níveis de impacto, com a descrição equivalente a cada nível, sendo que o N5 caracteriza-se como o melhor desempenho e o N1 como o pior desempenho, segundo percepção do decisor.

Consta ainda na Tabela 1, os níveis de referencias "BOM" e "NEUTRO", considerados ancoras que possibilitam estabelecer a integração entre os diversos descritores do modelo de avaliação. O Nível "BOM" determina o desempenho desejado pelo decisor para o respectivo descritor, enquanto o Nível "NEUTRO" estabelece o desempenho mínimo desejado para o descritor. O Nível "BOM" é marco divisor entre o desempenho ao nível de excelência e o desempenho à nível competitivo, enquanto o Nível "NEUTRO" estabelece o limite entre o desempenho à nível competitivo e o desempenho à nível comprometedor (GAMBA, 2012).

\subsection{Avaliação do modelo}

A etapa de avaliação envolve os seguintes procedimentos: (i) construção do modelo de preferência local - escalas cardinais; (ii) determinação das taxas de substituição (construção de uma função de valor que represente as preferências do decisor em relação a um determinado critério); (iii) avaliação global (agregação das avaliações locais em um critério único de síntese).

O modelo de preferencia local, consiste na transformação das escalas ordinais, adotadas na construção dos descritores em escalas cardinais locais através da função de valor que possiblita parâmetros para agregar o desempenho particular de um conjunto de critérios em um único valor, utilizando-se as taxas de substituição (COSTA et al., 2008).

A função de valor determina a diferença de atratividade entre os níveis de impacto de um mesmo descritor (DUTRA, 1998). Para sua construção o decisor analisa cada descritor individualmente e determina o quão atrativo um nível de desempenho é em relação a outro nível, conforme expõe a Figura 5. 
Figura 5: Função de valor para o descritor 2.2.2 Metodologia de avaliação dos serviços

2.2.2 Metodologia de Avaliação dos Serviços

Objetivo: Objetiva medir as formas adotadas de avaliação dos serviços prestados pela incubadora

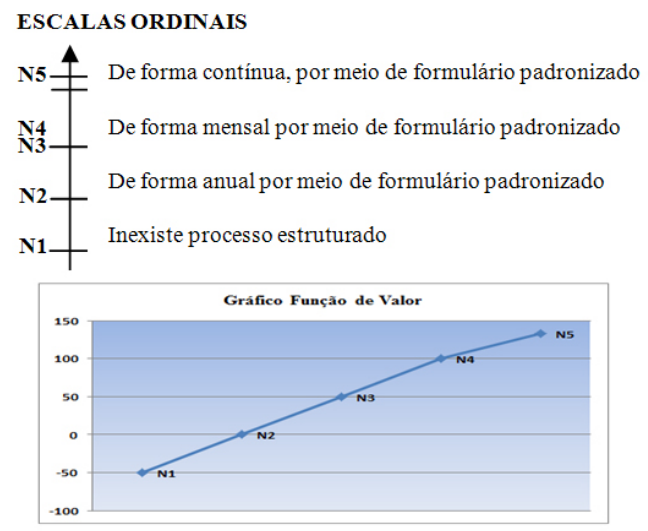

ESCALAS CARDINAIS

\begin{tabular}{|c|c|c|c|c|c|c|c|}
\hline \multicolumn{7}{|c|}{ W. 2.2.2 Metodologia de avaliação dos Serviços } & \multirow{2}{*}{$\begin{array}{l}x \\
\text { extrema } \\
\text { mt. forte }\end{array}$} \\
\hline 园 & N5 & N4 & N3 & $\mathrm{N} 2$ & N1 & \begin{tabular}{|c|} 
Escala \\
atual \\
\end{tabular} & \\
\hline N5 & nula & frac-mod & moderada & moderada & forte & 133.33 & forte \\
\hline $\mathrm{N} 4$ & & nula & moderada & moderada & forte & 100.00 & moderada \\
\hline N3 & & & nula & moderada & moderada & 50.00 & fraca \\
\hline N2 & & & & nula & moderada & 0.00 & mt. fraca \\
\hline N1 & & & & & nula & -50.00 & nula \\
\hline \multicolumn{8}{|c|}{ Julgamentos consistentes } \\
\hline 圊? & & +5 国 & 绍| & 思 & 담 & & \\
\hline
\end{tabular}

Fonte: Dos autores, 2012

A partir das opções de desempenho para o descritor 2. 2.2 Metodologia de avaliação dos Serviços - N1, N2, N3, N4, N5 - representadas na Figura 5, cabe ao decisor determinar o grau de atratividade em cada par de alternativas, com o uso do software Measuring Attactivenessby a Categorical Based Evaluation Technic (Macbeth), como ferramenta de apoio utilizada para o cálculo das funções de valor e das taxas de substituição.

O Software Macbeth emprega um método interativo para fins de quantificação dos julgamentos preferenciais realizados pelo decisor referente ao contexto em análise, utilizando um conjunto semântico ordinal para expressar o grau de atratividade dos níveis de um descritor (GAMBA, 2012).

Na aplicação do software Macbeth os níveis âncoras "bom" e "neutro" atribuem-se a pontuação 100 e 0, respectivamente, visando manter o mesmo grau de atratividade em qualquer descritor do modelo.

O procedimento seguinte da etapa de avaliação do modelo consiste na definição das taxas de substituição que expressam a perda de desempenho que uma determinada ação potencial deve sofrer em um critério para fins de compensar o ganho de desempenho em outro, a partir do julgamento do decisor.

Esse processo é necessário para integrar todos os julgamentos de diferenças de atratividade obtidos para os respectivos pontos de vista fundamentais, bem como identificar a importância relativa de cada critério para o modelo em questão, de acordo com o julgamento do decisor. A operacionalização das taxas de substituição também é realizada com a aplicação do software Macbeth (vide Figura 6). 


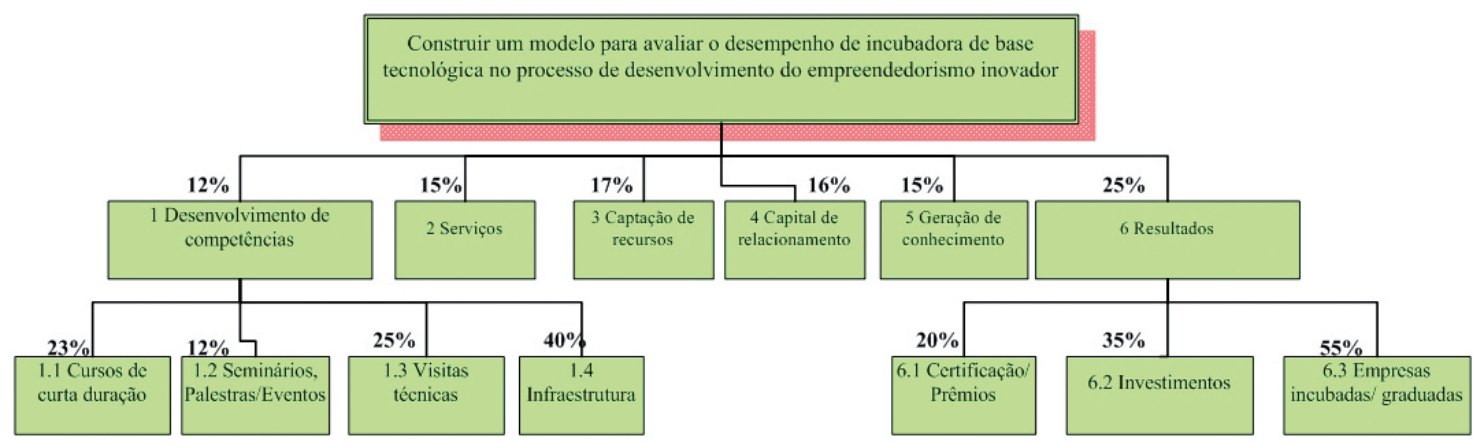

Fonte: Dos autores (2012)

Os dados da figura 6 revelam que o decisor confere o grau de importancia das áreas de preocupação e PVFs de forma equilibrada. Entretanto, verifica-se maior importância dada pelo decisor à área de 6 Resultados, se estendendo ao seu respectivo PVF 6.3 Empresas incubadas/graduadas (55\%), bem como ao PVF 1.4 Infraestrutura (40\%) específico da área de 1 Desenvolvimento de competências.

Uma vez obtidas as taxas de substituição resta agora, realizar a avaliação global do modelo de avaliação de desempenho. A avaliação global do modelo é operacionalizada por meio de fórmula de agregação aditiva, que consiste na soma ponderada das pontuações obtidas em cada critério pelo seu peso (taxa de substituição) correspondente, conforme abaixo demonstrada.

Figura 7: Equação genérica para avaliação global de desempenho de uma organização

$$
\mathbf{V}(\mathbf{a})=\sum_{\mathbf{i}=\mathbf{1}}^{\mathbf{n}} \mathbf{W}_{\mathrm{i}} \cdot \mathrm{V}_{\mathrm{i}}(\mathbf{a})
$$

Onde:

V(a): valor global da ação a;

v1 (a), v2 (a)...vn (a): valores parciais da ação a nos critérios 1, 2,..n;

w1 (a), w2 (a)...wn (a): taxas de substituição dos critérios: 1,2,..n;

$\mathrm{n}=$ número de critérios do modelo 
Por conseguinte, para melhor visualização da perfomance de uma ação em potencial, nos eixos de avaliação do modelo, estabelece-se um perfil de impacto, neste caso de duas incubadoras que contemplam uma recorte da estrutura arborescente de valor, ou seja, exclusivamente dos PVF's e do primeiro nível dos PVE's. Cumpre esclarecer que os perfis de desempenho são fictícios e visam demonstrar a aderencia e alinhamento do modelo construído, conforme demonstra Figura 8.

Observar-se (Figura 8) que no eixo horizontal as flechas apontam para os PVFs, enquanto que no eixo vertical, marca-se o desempenho da ação em potencial. Os níveis Bom e Neutro estão representados por duas linhas horizontais, respectivamente nas cores verde e amarela. A marcação destas duas linhas se faz necessária, pois facilita a visualização do decisor sobre o desempenho da ação potencial acima das expectativas e onde esta ação deixa a desejar.

Figura 8: Perfis de impacto - incubadoras de base tecnológica: $X$ e $Y$

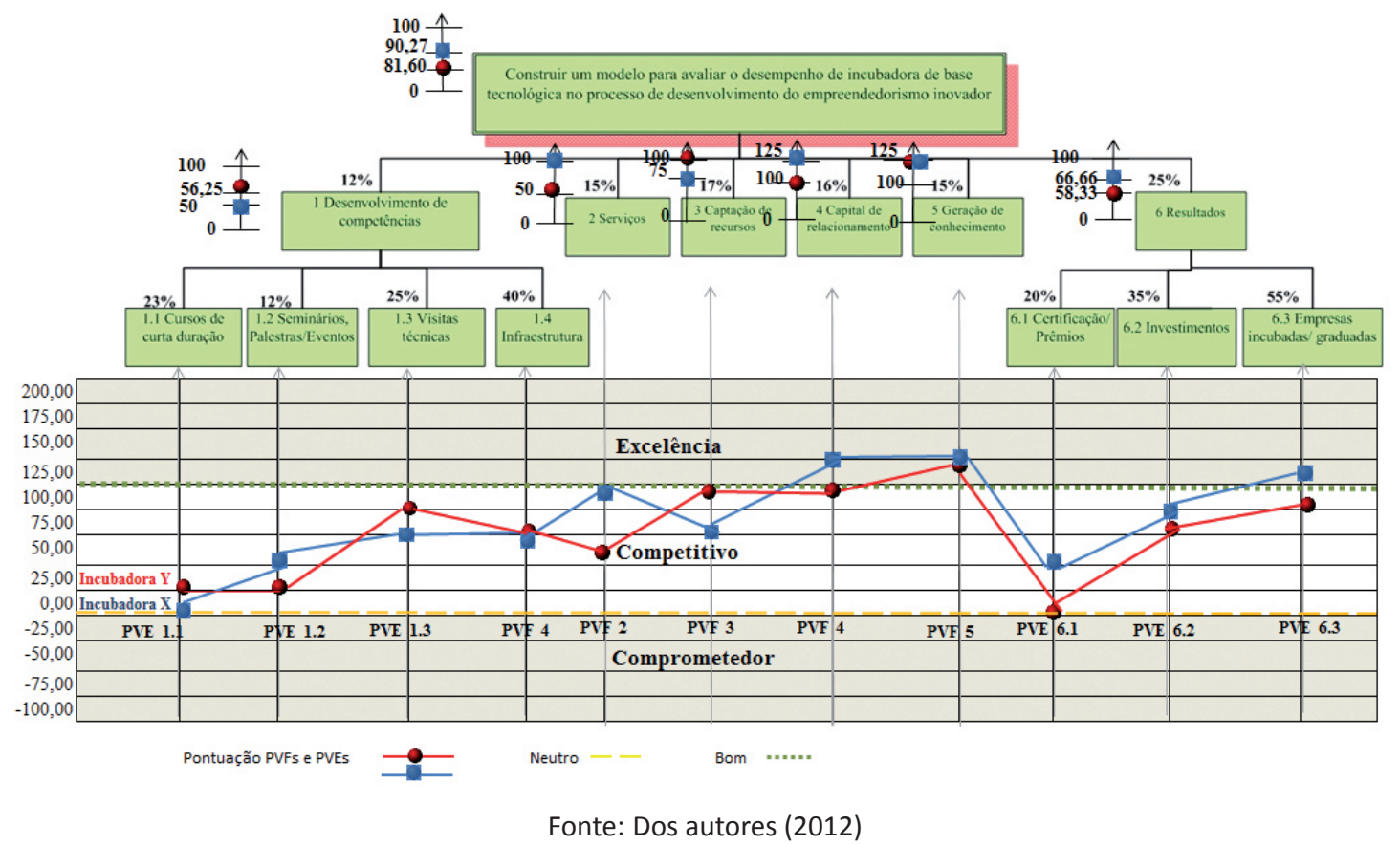

Com a ilustração pode-se verificar que a maior parte dos desempenhos encontra-se entre o nível Bom e Neutro, ou seja, um desempenho competitivo. Apresentando-se em dois critérios uma performance acima do nível Bom, PVFs: 4Capital de Relacionamento e 5 Geração de conhecimento, caracterizando-se como um desempenho de excelência. Observa-se ainda que nenhum dos PVF's ou PVE's atingiram desempenho comprometedor, ou seja, inferior a zero pontos. Adicionalmente nenhum dos critérios apresentou-se abaixo do nível Neutro. 
Tanto para a incubadora $X$, quanto para a $Y$, os pontos fracos estão relacionados principalmente ao PVF 1 Desenvolvimento de competências, especificamente nos PVE's 1.1Cursos de curta duração e 1.2 Seminários, Palestras, Eventos. Para a incubadora $X, 0$ PVE 6.1 Certificações, Prêmios, obteve uma performance próxima a zero.

Neste ponto, cabe lembrar que todos os PVF's e PVE's foram construídos com base na percepção do decisor e facilitadores utilizando-se da escolha de descritores que exclusivamente representassem as contribuições que as incubadoras propiciam na geração do empreendedorismo inovador, ou seja, não se construiu um modelo que avalia o desempenho das incubadoras de forma global, mas sim, de pontos específicos julgados como potencializadores de inovação.

Frente ao exposto, o desempenho global da incubadora $X$ em uma escala de 0 a 100 , atingiu 90,27 pontos, enquanto o desempenho da incubadora $Y$ atingiu 81,60 pontos. Da mesma, forma é possível identificar a pontuação obtida em cada PVF e PVE.

A partir dos pontos fracos identificados, surgem as oportunidades de melhoria, que são discutidas na seção, a seguir.

\subsection{Recomendações}

A Fase de Recomendações tem como objetivo apresentar ações a serem desenvolvidas a fim de permitir melhorar a performance global do modelo, tendo como referência o resultado apresentado na Fase de Avaliação (avaliação global do modelo). De acordo com Ensslin, Montibeller e Noronha (2001), esta fase pode gerar oportunidades de melhoria de forma pontual, para cada descritor, de forma local para cada PVE e/ou PVF, ou de forma global, considerando o desempenho total obtido por cada incubadora.

A partir da implementação de ações de melhoria é possível simular o impacto no desempenho de forma local e global, considerando o modelo de avaliação construído. Recomenda-se iniciar o processso de formulação de ações de melhoria para os descritores que apresentaram uma performance comprometedora, analisando também o impacto de tal melhoria no desempenho global construído para a incubadora. A Figura 9 apresenta o perfil de impacto com as ações de melhoria, exclusivamente para a incubadora Y. Foram consideradas ações de melhoria para o PVE 1.1; PVE 1.2, PVF 2 e PVE 6.1, conforme destaque. 
Figura 9: Perfil de impacto incubadora $Y$ com as ações de melhoria

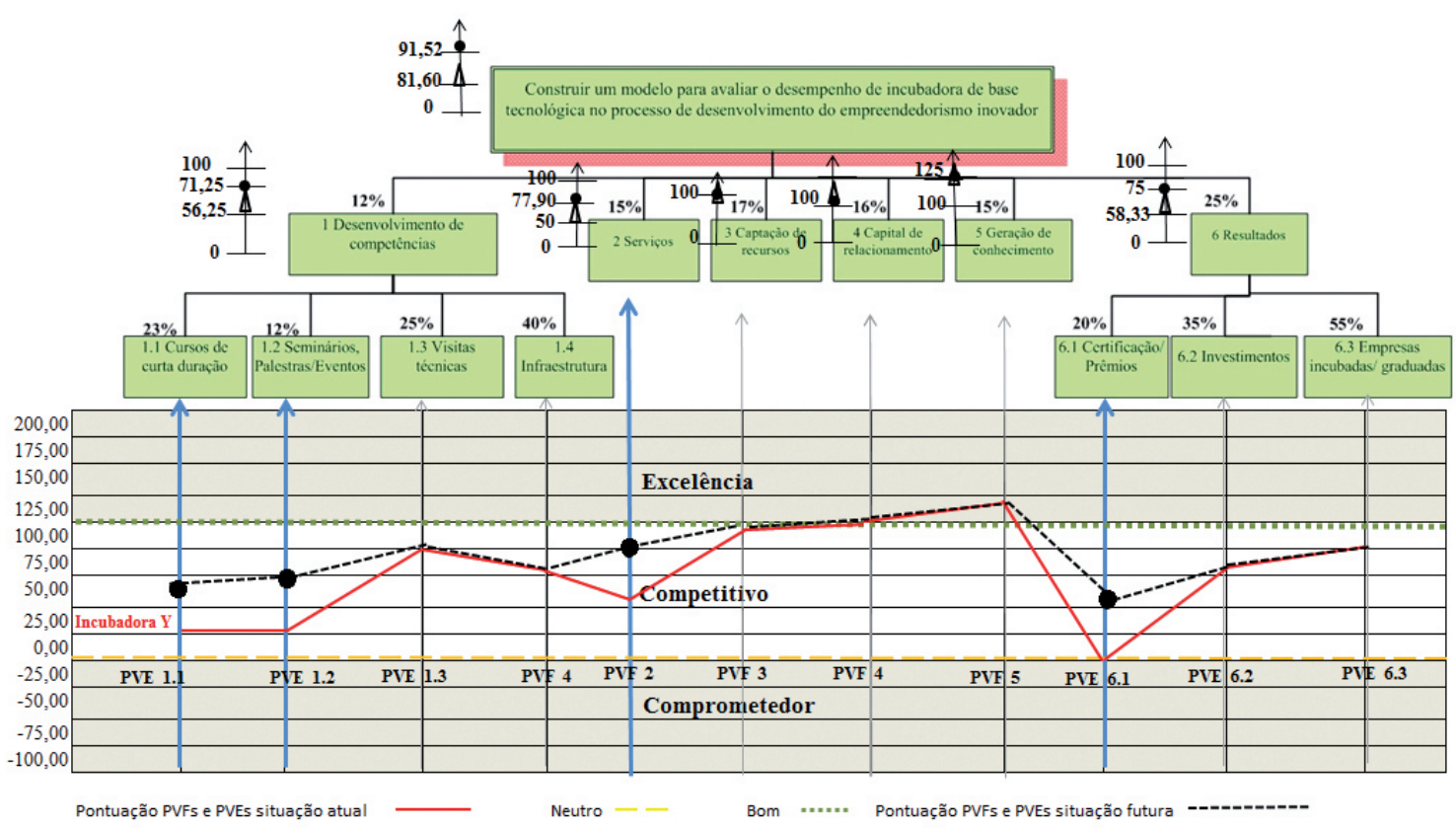

Fonte: Dos autores (2012)

Pode-se perceber na Figura 9 que com a implantação das estratégias de melhoria o desempenho global da incubadora $Y$ passou de 81,60 pontos para 91,52 pontos, a partir das ações empreendidas de forma local, nos PVEs 1.1, 1.2, 6.1 e no PVF 2.

A Metodologia MCDA-C, de caráter construtivista, utilizada neste estudo que resultou em um modelo para avaliar o empreendedorismo inovador gerado por incubadora de base tecnológica, possibilitou aos as atores envolvidos no processo, em especial ao decisor, aumentar o entendimento sobre os critérios que contribuírem para a geração da inovação. Também permitiu organizar tais critérios, mensurá-los e a partir do perfil do desempenho atual, apresentar recomendações de melhoria gerando um novo perfil de desempenho.

Destaca-se, que a estruturação do modelo apresentado neste artigo se diferencia em relação aos estudos similares, por organizar, mensurar e agregar a performance dos critérios que contribuem para a geração do empreendedorismo inovador em uma incubadora de base tecnológica e não seu desempenho num todo. 


\section{CONSIDERAÇÕES FINAIS}

O empreendedorismo inovador tem sido destaque na busca intensiva pelo desenvolvimento econômico e social dos países, sobretudo por seu viés tecnológico, determinante para vantagem competitiva nos tempos atuais. Em consonância percebe-se o crescimento exponencial de mecanismos que estimulem este fenômeno, destacandose nesta pesquisa, a incubadora de base tecnológica que age como propulsora do desenvolvimento de empresas de base tecnológica; provê um ambiente propício à criação e desenvolvimento de micro e pequenas empresas essencialmente inovadoras; desencadeia o desenvolvimento econômico; difunde, cria e aprimora o conhecimento; gera postos de trabalho e renda, além de alavancar o processo de empreendedorismo inovador.

O presente artigo teve como objetivo construir um modelo multicritério de avaliação que possibilite identificar a contribuição da incubadora de base tecnológica na geração do empreendedorismo inovador. O modelo construído evidenciou as preocupações e critérios considerados pelo decisor na geração do empreendedorismo inovador. Por meio da Metodologia MCDA-C estes critérios foram organizados, mensurados e integrados, possibilitando identificar o perfil de desempenho local e global de uma incubadora.

Assim, a partir das contribuições da Metodologia MCDA-C, foi possível identificar e mensurar o esforço gerado por uma incubadora no processo de desenvolvimento do empreendedorismo inovador, já que tanto os modelos abordados na literatura, bem como os estudos similares deixam lacunas no processo avaliação.

Sugere-se como estudos futuros a análise da contribuição do ambiente regulatório no processo de desenvolvimento do empreendedorismo inovador, além da aplicação real do modelo aqui proposto em uma incubadora específica para avaliar a consistência, a aderência e o alinhamento do modelo, permitindo uma maior sintonia entre as interfaces teóricas e empíricas a cerca do tema, objeto desta pesquisa. 


\title{
A MULTICRITERIA MODEL TO ASSESSING THE CONTRIBUTION OF THE TECHNOLOGY-BASED INCUBATOR IN THE GENERATION OF INNOVATIVE ENTREPRENEURSHIP
}

\begin{abstract}
The technology-based incubator plays a unique role in fostering innovative entrepreneurship, a phenomenon considered crucial in the intensive search for economic and social countries development. However, the actual contribution that this mechanism plays to innovative entrepreneurship is unknown, given the lack of models that perform such evaluation. Therefore, this research proposes the construction of a multicriteria assessment model for contribution of technology-based incubator of innovative entrepreneurship generation. The Multicriteria Support Decision - Constructivist (MCSD-C) methodology was used as an instrument of intervention. This case study takes a constructivist view of knowledge and has an exploratory nature. The data source is primary or secondary in nature and the methodological approach can be classified as qualitative and quantitative. Results evidenced that the Multicriteria methodology has proven to be consistent when provides knowledge about the construction of an evaluation model which considers incubated companies as a unique mechanism in promoting innovative entrepreneurship. In addition, it provides an instrument which allows the management of the process of innovative entrepreneurship and turns efforts into improvements performance activities.
\end{abstract}

Keywords: Innovative entrepreneurship.Technology-based incubator. Performance assessment. Multicriteria methodology.

\section{REFERÊNCIAS}

ASSOCIAÇÃO NACIONAL DE ENTIDADES PROMOTORAS DE EMPREENDIMENTOS INOVADORES. Agenda das cidades empreendedoras e inovadoras. 2004. Disponível em:< http://www.anprotec.org.br/ArquivosDin/anprotec_agendadascidades_pdf_33. pdf>. Acesso em: 15 fev. 2012.

Brasil é o terceiro do mundo e primeiro da América Latina em número de incubadoras de empresas. 2002. Disponível em: <http://www.anprotec.org.br/ publicacao.php?idpublicacao=159>. Acesso em: 20 nov. 2011. 
Panorama ANPROTEC. 2006. Disponível em: <http://www.anprotec.org.br/ secaopanorama.php> Acesso em: 27 maio 2011.

ARANHA, J. A. S. Incubadoras. In: PAROLIN, S.R.H.; VOLPATO, M. Faces do Empreendedorismo Inovador. Curitiba: SENAI/SESI/IEL, 2008. p.37-65.

BAÊTA, A. M. C. O desafio da criação: uma análise das incubadoras de empresas de base tecnológica. Petrópolis: Vozes, 1999.

BANA E COSTA, C. A. Structuration, Construction et Exploitation dúnModèleMulticritèred'Aide à la Decision. 1992. Thèse (DoctoratenIngénierie de Systèmes)- Universidade Técnica de Lisboa, Instituto Superior Técnico, 1992.

BARBIERI, J. C. (Org.) Organizações Inovadoras: estudos e casos brasileiros. Rio de Janeiro: FGV, 2003.

BELTON, V. Multiple criteria decision analysis - practically the only way to choose. In: HENDRY, L. C.; EGLESE, R. W. (Ed.).Operational research tutorial papers. Birmingham: OR Society, 1990.

BORTOLUZZI, S. C.; ENSSLIN, S. R.; ENSSLIN, L. Avaliação de desempenho das variáveis financeiras e não financeiras que respondem pelo desempenho de uma indústria de móveis. Revista Gestão Industrial, Ponta Grossa, v. 7, p. 24-47, 2011.

CHALELA, L.R. O empreendedorismo e a inovação em ambientes de incubação. 2008. 187 p. Dissertação (Mestrado em administração) - Universidade de Caxias do Sul, Caxias do Sul, 2008.

COSTA, J. M. et al. Desempenho Agregado: A construção de um modelo de avaliação. In: ENCONTRO NACIONAL DE ENGENHARIA DE PRODUÇÃO, 28, 2008. Rio de Janeiro. Anais... Rio de Janeiro: ABEPRO, 2008.

DOLABELA, F. Oficina do empreendedor: a metodologia de ensino que ajuda a transformar conhecimento em riqueza. São Paulo: Cultura Editores Associados, 1999.

DRUCKER, P.F.Inovação e Espírito Empreendedor: Práticas e princípios. Tradução de Carlos Malferrari. São Paulo: Cengage Learning, 2010.

DUTRA, A. Elaboração de um sistema de avaliação de desempenho dos recursos humanos da Secretaria de Estado da Administração - SEA à luz da metodologia multicritério de apoio à decisão. 1998. 443 f. Dissertação (Mestrado em Engenharia de Produção)- Curso de Pós-Graduação em Engenharia de Produção, Universidade Federal de Santa Catarina, Florianópolis, 1998.

DUTRA, A. et al. A incorporação da dimensão integrativa nos processos de avaliação do desempenho organizacional: um estudo de caso. RevistaContemporânea de Contabilidade (UFSC), Florianópolis, v. 6, p. 109-136, 2009. 
ENSSLIN, L.; DUTRA, A.; ENSSLIN, S. R. MCDA: a constructivist approach the management of human resources at a governmental agency. InternationalTransactions in OperationalResearch, n. 7, p. 79-100, 2000.

ENSSLIN, L. et al. Identificando e analisando problemas de performance: o uso da avaliação de desempenho (Feedback, Coaching e Counseling) para melhorar a produtividade dos empregados. Florianópolis: UFSC, 2007. (Apostila da disciplina EPS 7007 - Avaliação de Desempenho; 1ㅇsemetre, 2007).

ENSSLIN, L. et al. Avaliação do Desempenho de Empresas Terceirizadas com o Uso da Metodologia Multicritério de Apoio à Decisão- Construtivista. Revista Pesquisa Operacional, Rio de Janeiro, v.30, n. 1, p. 125-152, 2010.

ENSSLIN, L.; MONTIBELLER, G.; NORONHA, S. M. Apoio à Decisão: Metodologias para Estruturação de Problemas e Avaliação Multicritério de Alternativas. Florianópolis: Insular, 2001.

ETZKOWITZ, H. Incubation of incubators: innovation as a triple helix of university industrygovernment networks, Science and Public Policy, v. 29, n. 2, p. 115-128, 2002.

FARBER, S. G.; HOELTGEBAUM, M.; KLEMZ, B. Rede de cooperação em produção científica do EGEPE de estudos sobre empreendedorismo e gestão de pequenas empresas. Revista de Administração e Inovação - RAI, São Paulo, v. 8, n. 3, p.141-161, 2011. Disponível em: <http://www.revistarai.org/rai/article/view/809/pdf_44>. Acesso em: 01 out. 2012.

GALLON, A.V.; ENSSLIN, R.S.; ENSSLIN, L. Avaliação de desempenho organizacional em incubadoras de empresas por meio da metodologia multicritério de apoio à decisão construtivista (MCDA-C): a experiência do midi tecnológico. Revista de Administração e Inovação - RAI, São Paulo, v. 8, n. 1 , p.37 - 63, jan./mar. 2011.

GAMBA, J. J. Avaliação do desempenho do serviço de atendimento emergencial realizado pelo corpo de bombeiros militar, fundamentado na metodologia multicritério de apoio à decisão construtivista - MCDA-C. 2012. 271 f. Dissertação (Mestrado em Administração)- Universidade do Sul de Santa Catarina-Unisul, Florianópolis, 2012.

GIFFHORN, E. Construção de modelo de avaliação de desempenho de empresas terceirizadas com a utilização da metodologia MCDA-C. 2007. Dissertação (Mestrado em Engenharia de Produção)-Universidade Federal de Santa Catarina - UFSC, Florianópolis, 2007.

GIL, A. C. Métodos e Técnicas de Pesquisa Social. 3. ed. São Paulo: Atlas, 1991.

HMELJEVSKI, J. I. Modelo de avaliação do desempenho da área de operações comerciais de uma rede de emissoras de televisão. 2007. Dissertação (Mestrado em Engenharia de Produção)- Universidade Federal de Santa Catarina - UFSC, Florianópolis, 2007. 
JABOUR, C.; DIAS, P.; FONSECA, S. A performance de incubadoras empresariais do interior paulista à luz de um novo modelo de avaliação de desempenho. Revista Produção Online, Florianópolis, v. 5, n.4,p.18, dez./abr. 2005. Disponível em: < http:// www.producaoonline.org.br/rpo/article/view/366/449 >. Acesso em: 14 maio 2012.

JABOUR, C.; DIAS, P.; FONSECA, S. As incubadoras empresariais como redes de empresas pró-inovação. In: SIMPÓSIO DE ENGENHARIA DE PRODUÇÃO, 6., 2004. Bauru. Anais... Bauru: SIMPEP (UNESP), 2004.

KANTER, R.; KAO, J.; WIERSEMA, F. Pensamento inovador na 3M, DuPont, GE, Pfizer e Rubbermaid: acesso instantâneo às estratégias de ponta da atualidade. Tradução: June Camargo. São Paulo: Negócio Editora, 1998.

KEENEY, R. L. Value-focused thinking: a path to creative decision-making. Cambridge: Harvard Univ. Press., 1992.

LACERDA, R. T. O. ; ENSSLIN, L ; ENSSLIN, S. R. A performance measurement view of IT project management. The International Journal of Productivity and Performance Management, v. 60, p. 132-151, 2011a.

LACERDA, R. T. O. ; ENSSLIN, L.; ENSSLIN, S. R. A performance measurement framework in portfolio management A constructivist case. Management Decision, v. 49, p. 648-668, 2011b.

LASTRES, H. M. M; CASSIOLATO, J.E. Glossário de arranjos e sistemas produtivos e inovativos locais. [S.I.: s.n.], 2003. Disponível em: < http://www.loures.ecn.br/td_ redesist/glossario.pdf >. Acesso em: 15 fev. 2012.

LIMA, A. A. T. et al. Sistema de avaliação de desempenho de incubadoras de empresas de base tecnológica a luz da inovação tecnológica: uma discussão sobre os sobre os modelos existentes. Ciências Sociais Aplicadas em Revista, Marechal Cândido Rondon, v.8, n.15, p. 57-73, jul./dez. 2008.

LUNDVALL, B. A. National systems of innovation: towards a theory of innovation and interactive learning. London: Pinter Publ., 1992.

MAEHLER, A. E. Interação e contribuição de incubadora e universidade no desenvolvimento de pequenas empresas. 2005. 152 f. Dissertação de Mestrado (Mestrado em Administração)- Universidade Federal de Santa Maria,Santa Maria, 2005.

MANTOVANI, D. M. N. et al. O papel das incubadoras de empresas no desenvolvimento local: um estudo de caso. Revista de Administração e Inovação - RAI, São Paulo, v. 3, n. 1, p. 90-101, 2006.

MERRIAM, S. B. Qualitative research and case study applications in education. San Francisco: Allyn and Bacon, 1998. p. 4-25. 
MORAES, L. et al. The Multicriteria Analysis for construction of Benchmarkers to Support the Clinical Engineering in the Healthcare Technology Management. EuropeanJournalofOperationalResearch, v. 200, p. 607-615, 2010.

MONTIBELLER, G. N. Mapas cognitivos difusos para o Apoio à Decisão. 2000.Tese (Doutorado em Engenharia de Produção)-Universidade Federal de Santa Catarina UFSC, Florianópolis, 2000.

MOTTA, E.; IMONIANA, J. O. Proposição de sistema de gestão e monitoramento do desempenho para empresas incubadas de base tecnológica. Revista Eletrônica de Gestão de Negócios e Gestão, v. 1, n. 1, p. 60-82, abr./jun. 2005.

OSBORN, A. F. Applied imagination.3th ed. Buffalo: Creative Education Foundation, 1993.

PINTO, J. P. M. Estrutura do conhecimento e dinâmica do aprendizado em processos de incubação de empresas: estudos de caso na incubadora CELTA em Florianópolis. 2006. 144f. Dissertação (Mestrado em Economia)- Universidade Federal de Santa Catarina, Florianópolis, 2006.

RAUPP, F. M.; BEUREN, I.M. O suporte das incubadoras brasileiras para potencializar as características empreendedoras nas empresas incubadas. Revista de Administração da Universidade de São Paulo - RAUSP, São Paulo, v.41, n. 4, p.1-16, out./dez. 2006.

RICHARDSON, R. J. Pesquisa Social: métodos e técnicas. 3. ed. São Paulo: Atlas, 1999.

ROY, B. Decision science or Decision-Aid Science. European Journal of Operational Research, n.66, p. 184-203, 1993.

ROY, B. Multicriteria methodology for decision aiding. Dordrecht: KluwerAcademicPublishers, 1996.

SARKAR, S. O empreendedor inovador: faça diferente e conquiste seu espaço no mercado. Rio de Janeiro: Elsevier, 2008.

SCHUMPETER, J. A. Business Cycles: A Theoretical, Historical and Statistical Analysis of the Capitalist Process. New York Toronto London : McGraw-Hill Book Company, 1939, 461 pp. Abridged, with an introduction, by RendigsFels. Éditionélectroniqueréaliséeav ecletraitement de textes Microsoft Word 2004 pourMacintosh.Disponível em < http:// classiques.uqac.ca/classiques/Schumpeter_joseph/business_cycles/schumpeter_ business_cycles.pdf>. Acesso em: 02 nov. 2011.

Teoria do desenvolvimento econômico (Os Economistas): uma investigação sobre lucros, capital, crédito, juro e o ciclo econômico. Introdução de Rubens Vaz da Costa. Tradução de Maria Sílvia Possas. São Paulo: Abril Cultural, 1982.

The theory of economic development. Cambridge, MA: Harvard University Press, 1934. 
SWEDBERG, R. Entrepreneurship: The Social Science View. First published. New York: Oxford University Press, 2000.

TERRA, J. C. C. Processos de Inovação. 2010. Terra Fórum Consultores. Disponível em:< A12http://biblioteca.terraforum.com.br/BibliotecaArtigo/Forms/DispForm.aspx?ID=2 72\&Source=http\%3A\%2F\%2Fbiblioteca\%2Eterraforum\%2Ecom\%2Ebr\%2FBibliotecaArt igo\%2FForms\%2FAllItems\%2Easpx\%3FPaged\%3DTRUE\%26p_DCDateCreated\%3D201 00428\%252018\%253a18\%253a22\%26p_ID\%3D279\%26View\%3D\%257b222E5C71\%25 2dD580\%252d4DD0\%252dAD4A\%252dE7053A71A48E\%257d\%26FolderCTID\%3D0x01 2001\%26PageFirstRow\%3D101\&RootFolder=\%2FBibliotecaArtigo>. Acesso em 01 mar. 2012.

VEGINI, D. et al. O. Modelo de avaliação de desempenho de fogões com foco em ergonomia, utilizando o método MCDA-C. Revista Produção Online, Florianópolis,v.12, n. 2, p. 423-454, abr./jun. 2012.

VEDOVELLO, C., FIGUEREDO, P. N. Incubadora de Inovação: Que espécie é essa? RMIRede Mineira de Inovação. Catálogo 2007/2009 - SECTES/MG e SEBRAE/MG. RAEeletrônica, v. 4, n. 1, Art. 10, jan./jul. 2005.

ZAMCOPÉ, F. C. et al. A. Modelo para avaliar o desempenho de operadores logísticos um estudo de caso na indústria têxtil. Revista Gestão \& Produção, São Carlos, v. 17, n. 4, p. 1-13, 2010.

ZANELATO, R. Construção de um modelo de avaliação de desempenho de serviços de suporte e operação na área de tecnologia da informação com a utilização da metodologia MCDA-C. 2008. Dissertação (Mestrado em Engenharia de Produção)Universidade Federal de Santa Catarina - UFSC, Florianópolis, 2008. 


\section{SOBRE OS AUTORES}

\begin{tabular}{|l|l|} 
Graduado em Administração pela Universidade Federal de Santa Catarina (UFSC). \\
Pela mesma Universidade, possui especialização em Administração de Recursos \\
Humanos, especialização em Gestão da Qualidade e Produtividade, Mestrado \\
e Doutorado em Engenharia de Produção. Atualmente é professor titular da \\
Universidade do Sul de Santa Catarina (Unisul), Membro de corpo editorial da \\
Revista Contemporânea de Contabilidade e Revista Eletrônica de Estratégia \\
\& Negócios (REEN) - Unisul. Revisor de periódico da Revista de Ciências da \\
Administração (CAD/UFSC), Revista do CCEI, Revista de Administração Pública \\
(Impresso) e da Revista de Administração da UFSM. Tem experiência na área de \\
Administração, com ênfase em Avaliação de Desempenho Organizacional.
\end{tabular}

Graduada em Sistemas de Informação pela Universidade do Sul de Santa
Catarina - Unisul. Atuou como desenvolvedora e analista na área de tradução
(tradução de dados bancários) da empresa Nexxera Tecnologia e Serviços S.A.
sediada em Florianópolis. Atualmente é Mestranda em Administração na linha
de Estratégia pela Unisul e bolsista com exclusividade pela CAPES. Editora de
layout da Revista Eletrônica de Estratégia \& Negócios (REEN).

Mestrandoem Administração-Unisul/SC(2011);AdministraçãoEstratégica(Unisul
- 2003); Pós-Graduado em Finanças (UFSC - 2001) com Graduação em Economia
(UFSC - 1983). Controller - Empresa SchaeferYachts - Florianópolis. Professor -
ênfase em Administração Financeira, Custos Industriais e Controladoria. Áreas/
Temas de interesse: Controladoria, BalancedSocrecard(BSC), Metodologia
Multicritério de Apoio à Decisão Construtivista (MCDA-C), Avaliação de
Desempenho Organizacional, Planejamento e Controle Orçamentário, Custos
Industriais e Estudos de Viabilidade Econômico-Financeira.




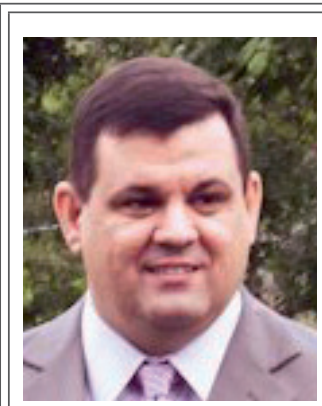

José Carlos

Martinazzo

Júnior

Graduado em Ciência da Computação pela Universidade do Oeste de Santa Catarina (UNOESC). Pela Universidade Federal de Santa Catarina (UFSC), possui especialização em Automação e Sistemas. Mestrando em Administração na linha de Estratégia pela Universidade do Sul de Santa Catarina (UNISUL). Atualmente é Especialista em Tecnologia do Serviço Nacional de Aprendizagem Industrial (SENAI/SC), com função de Coordenação da Rede SENAI/SC de Laboratórios de Metrologia.

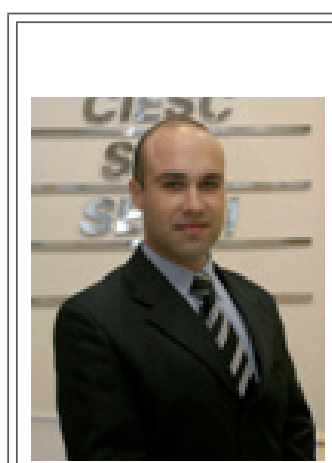

Maicon Lacerda

Administrador de Empresas e Pedagogo graduado pela Universidade do Sul de Santa Catarina (UNISUL) e pós-graduado em Gestão Empresarial pela Fundação Getúlio Vargas (FGV). Mestrando em Administração pela Universidade do Vale do Itajaí (UNIVALI). É Lead Assessor na NBR ISO 9001:2008, atuou por mais de cinco anos como consultor de empresas para implantação de sistemas de gestão, examinador da Fundação Nacional da Qualidade (FNQ) nos ciclos de 2008, 2009, 2010, 2011 e 2012, instrutor, conteudista de cursos à distância e auditor nas áreas de gestão da qualidade, processos e fornecedores. Coordenou o Núcleo de Gestão Empresarial do SENAI/SC em Florianópolis no período de 2009 a 2011. Atualmente é Coordenador de Projetos do Núcleo de Tecnologia e Inovação na Direção Regional do SENAI/SC. 